\title{
Empirical recurrence risk after unidentified multiple congenital abnormalities
}

\author{
A CZEIZEL AND JULIA MÉTNEKI
}

From the Department of Human Genetics, National Institute of Hygiene, Budapest, Hungary.

SUMmaRY Thirty-five fetal deaths $(30.4 \%)$ and 12 cases of congenital abnormality $(15 \cdot 0 \%)$ occurred in 117 subsequent pregnancies and 80 sibs of 112 consultands who had babies with unidentified multiple congenital abnormalities after genetic counselling. The specific recurrence risk of unidentified multiple congenital abnormalities was $5 \%$.

The identification of multiple congenital abnormalities (MCA), that is, two or more different major congenital abnormalities in the same person, ${ }^{1}$ is important from several points of view. For example, the estimation of prognosis and recurrence risk are much more accurate in recognised syndromes than in unidentified MCA. In genetic counselling clinics MCA have caused many difficulties. The identification of several recognisable but rare or not uniformly expressed MCA is not an easy task, and a considerable number of MCA are not delineated as entities. Probands with unidentified MCA represented $2.2 \%$ of the material in our genetic counselling clinic from 1975 to 1980 . According to Roberts, ${ }^{2}$ "Any medical advice is better than no advice" and this prompted us to determine the empirical recurrence risk of unidentified MCA. The so-called empirical risk figures deserve study until adequate theoretical models provide the necessary information. ${ }^{3}$

\section{Materials and methods}

There is a continuous follow-up study of consultands in our genetic counselling clinic. ${ }^{4}$ A reply-paid purpose designed postal questionnaire is sent to the address of consultands after 1 to 5 years of counselling. In this paper, the outcome of pregnancies of 112 consultands who have had a previous child with unidentified MCA is evaluated from the material of 1975 to 1980 . Data from all probands and their affected first degree relatives are based on medical documentation including necropsy reports.

\section{Results}

The outcome of 117 pregnancies of 112 consultands

Received for publication 7 January 1983.

Accepted for publication 19 February 1983. who had previously had babies with unidentified MCA was ascertained after counselling. Two induced abortions were reported and 35 spontaneous abortions $(30.4 \%)$ occurred in the remaining 115 pregnancies. This figure is higher than the recorded national value $(13 \%)$ in the period studied. Among 80 sibs, $12(15 \%)$ had congenital abnormalities (table); this is higher than both the registered Hungarian value (about $4 \%$ ) and the theoretical expectation (about $6 \%$ ). However, it is necessary to separate this figure into two categories. One category is affected sibs showing the specific recurrence. Four subsequent sibs had MCA resembling those in the proband.

\section{CASE $365 / 78$}

This stillborn male proband had spina bifida cystica within the MCA. Amniotic fluid AFP examination was done in the next pregnancy and it gave a normal value $(19.4 \mu \mathrm{g} / \mathrm{ml})$, but the child, a boy, again had a lethal MCA. The congenital abnormalities in these two MCA showed considerable similarity: bilateral split hands and feet as well as uni- or bilateral obstructive urological anomalies. The differences were a neural tube defect in the proband and a diaphragmatic hernia, Bochdalek type, in his brother. However, these abnormalities may have an aetiological relationship. ${ }^{56}$ An important point was that the mother also had MCA involving hydronephrosis, spina bifida occulta, and syndactyly of the fingers and toes. The familial cluster of these unidentified MCA suggests autosomal dominant inheritance. It is unlikely that these were cases of any of the recognised syndromes exhibiting digital and renal abnormalities, for example, acrorenal, trisomy 18, Weyers, SCE, Poland, LARD, Duane, or VACTERL. 


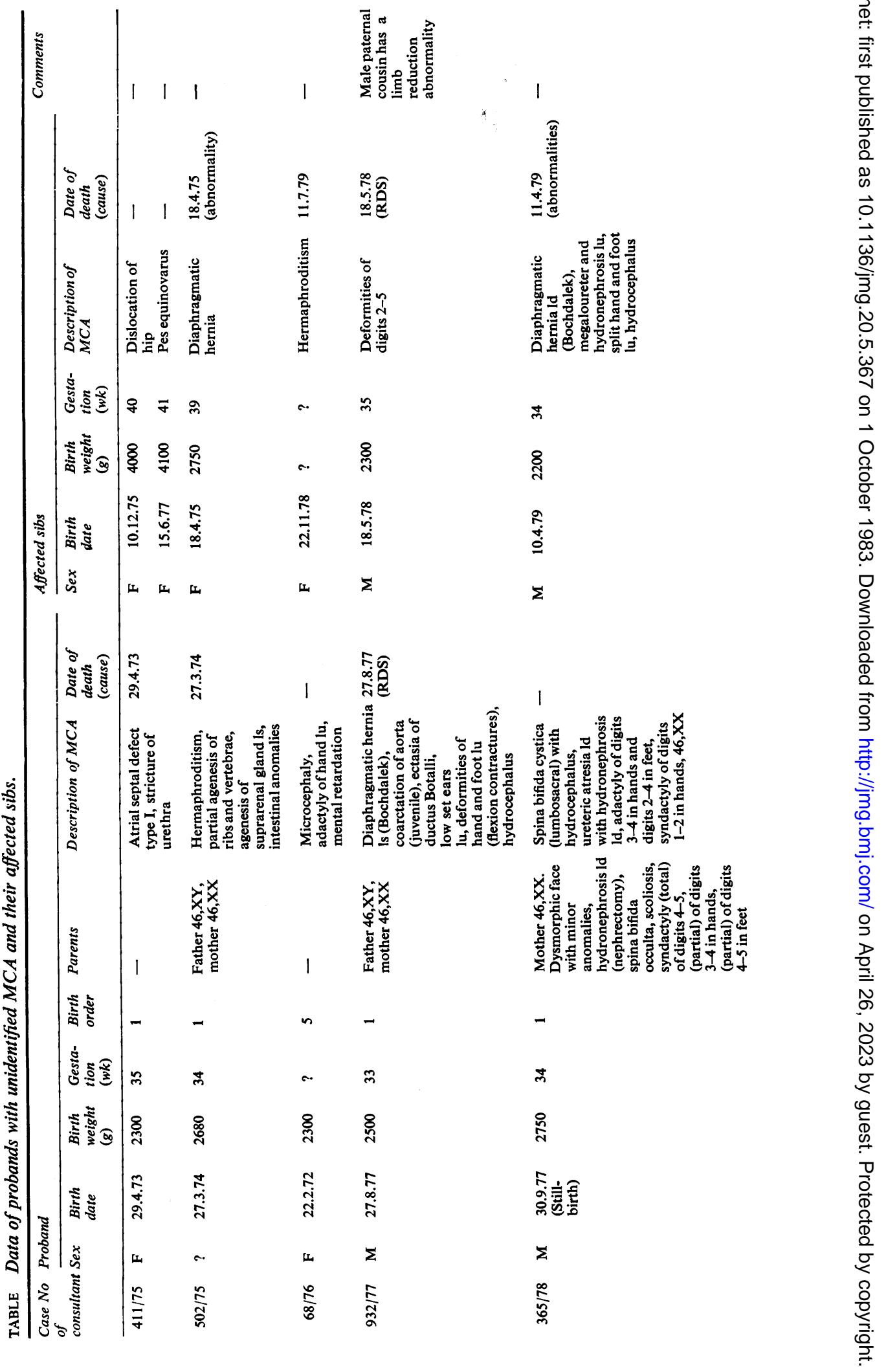




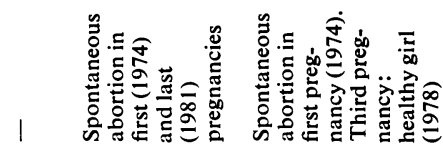

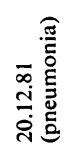

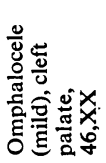

q

ষ্्্

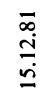

L

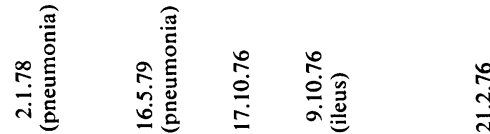

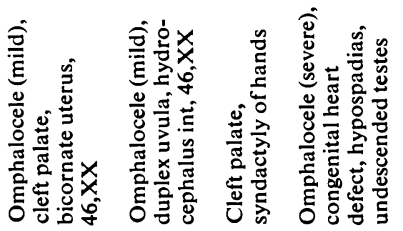
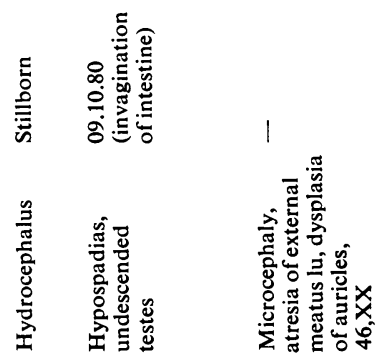

\&

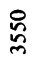

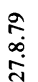

山 $\Sigma$

f $q$

잉 :

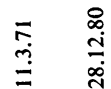

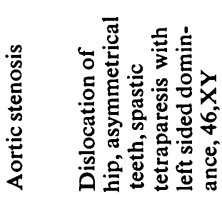

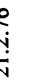

ลิ
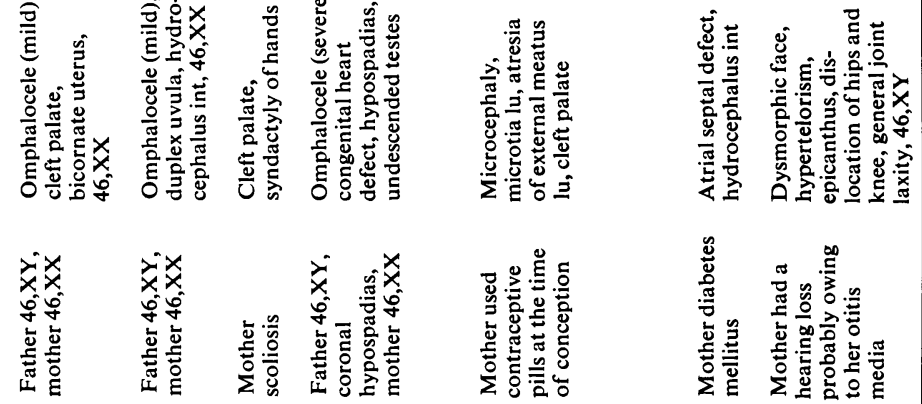

स $\approx \approx \pi$

요

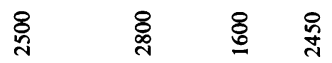

怘

品

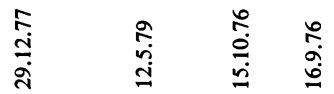

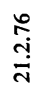

$\begin{array}{cc}\stackrel{1}{i} & 0 \\ 0 & 0 \\ 0 & 0\end{array}$

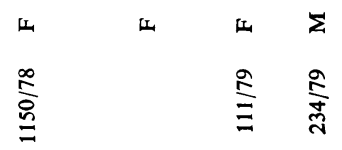

$\stackrel{5}{\stackrel{5}{5}}$

$\begin{array}{ll}\omega & \Sigma \\ \infty & \infty \\ \frac{\infty}{\infty} & \frac{\infty}{0} \\ & \frac{n}{0}\end{array}$ 
CASE $1150 / 78$

Both probands had similar MCA involving omphalocele and cleft palate (uvula duplex is considered to be its minor manifestation). The possibility of schisis association with a recurrence risk of $4 \% 5$ or an unknown autosomal recessive syndrome with $25 \%$ recurrence was considered. Amniotic fluid AFP examination showed a normal value (17.5 $\mu \mathrm{g} / \mathrm{ml})$. The third sib, a girl, had the same syndrome. The lethal outcome of all cases is inexplicable.

CASE $1917 / 79$

After the birth of a healthy female, an affected sister with MCA was born from the mother's fourth pregnancy. The paediatric consultant suggested Goldenhar syndrome on the basis of her and the proband's MCA, though vertebral and ocular anomalies were absent. Marked variability in the clinical picture of this syndrome is described. As far as we know only two other families have been reported with two affected sibs, suggesting autosomal recessive inheritance. ${ }^{6 a} 7$ Proto and Scullica ${ }^{8}$ and Summit ${ }^{9}$ reported two families with dominant inheritance of varying degrees of anomalies. However, in general, the aetiology of Goldenhar syndrome is not known and it usually has a sporadic manifestation. ${ }^{10}$

CASE $1615 / 80$

The second boy born after the counselling had similar but not identical MCA. On the basis of their phenotypes, in spite of the absence of a flat face with depressed nasal bridge, hand anomalies, and cleft lip or palate, Larsen syndrome was suggested by our consultants. According to Smith ${ }^{10}$ the aetiology of Larsen syndrome is unknown, but McKusick's catalogue lists Larsen syndrome as showing both autosomal dominant and autosomal recessive inheritance. One of the original cases of Larsen et $\mathbf{l l}^{11}$ had an affected child, but this syndrome is usually recessive as in our family.

\section{Discussion}

The study of the recurrence of unidentified MCA in sibs of probands often helps to clarify the diagnosis ${ }^{12}$ because the various abnormalities are more accurately represented in the affected sibs than in the atypical probands. Our series appears to delineate two unknown syndromes: a vertebral-hydronephrosis-limb (central axis) syndrome with autosomal dominant inheritance, and a cleft palateomphalocele syndrome with autosomal recessive inheritance. Furthermore, on the basis of this follow-up study, our consultants identified two atypical examples of recognised syndromes, $\stackrel{\mathbb{P}}{=}$ Goldenhar and Larsen. An important conclusion is $\overrightarrow{\overline{\vec{S}}}$ that all MCA in subsequently affected sibs seem to have an aetiological relationship with the unidentified MCA of probands.

The other category of congenital abnormalities in sibs are those which are probably unrelated to the unidentified MCA of the proband and have probably occurred by chance. Thus, the seven $\vec{\circ}$ isolated congenital abnormalities in sibs all appear to be coincidental. However, the validity of the $\vec{\omega}$ diagnosis of hydrocephalus in a stillborn baby (case 111/79) is not high. An aetiological relationship of the congenital heart defects in case 1253/80 and her sister, and the hand deformities in the proband or 932/77 and his affected brother, cannot be excluded. The 12th case $(234 / 79)$ is exceptional. The brother of the proband may have inherited hypospadias from the father and so it may not be coincidental. However, this abnormality is independent of the proband's MCA.

In summary, the specific recurrence risk of unidentified MCA in this series was $5.0 \%$, while the risk of probably unrelated congenital abnormalities was $8.8 \%$. The latter proportion is slightly, though not significantly, higher than the theoretical expectation and so a causal relationship in some instances could not be excluded.

\section{References}

1 Czeizel A. Definition of multiple congenital abnormalities. Acta Morphol Acad Sci Hung 1981 ;29:251-8.

2 Roberts JAF. An introduction to medical genetics. 3rd ed. London: Oxford University Press, 1965.

${ }^{3}$ Epstein CJ. Birth defects, dysmorphology and genetic counselling. Birth Defects $1979 ; 15,5 \mathrm{C}: 1-5$.

4 Czeizel A, Métneki J, Osztovics M. Evaluation of information-guidance in genetic counselling. $J$ Med Genet 1981 ;18:91-8.

5 Czeizel A. Schisis-association. Am J Med Genet 1981 ;10: 25-35.

${ }^{6}$ Fraser FC, Czeizel A, Hanson C. Increased frequency of $D$ neural tube defects in sibs of children with other malformations. Lancet 1982 ;ii:144-5.

6a Saraux H, Grignon JL, Dhermy P. A propos d'une $\widetilde{N}$ observation familiale de syndrome de Franceschetti- N Goldenhar. Bull Soc Ophtalmol Fr 1963;63:705-7.

7 Krause U. The syndrome of Goldenhar affecting two $\omega$ siblings. Acta Ophthalmol (Kbh) 1970;48:494-9.

8 Proto F, Scullica L. Contibuto allo studio della ereditarieta dei dermoidi epibulbari. Acta Genet Med Gemellol (Roma) 1966;15:351-63.

9 Summit RL. Familial Goldenhar syndrome. The clinical delineation of birth defects. II. Malformation syndromes. Birth Defects 1969;5,2:106-9.

10 Smith DW. Recognizable patterns of human malformations. Genetic, embryologic and clinical aspects. Philadelphia: Saunders, 1981. 
11 Larsen LJ, Schottstaedt ER, Bost FC. Multiple congenital dislocations associated with characteristic facial abnormality. J Pediatr 1950;37:574-81.

12 Fraser FC, Lytwyn A. Spectrum of anomalies in the Meckel syndrome. Am J Med Genet 1981 ;9:67-73.
Correspondence and requests for reprints to Dr A Czeizel, Department of Human Genetics, National Institute of Hygiene, Gyáli út 2-6, H-1966 Budapest, Hungary. 